Article

\title{
Foaming of Polycaprolactone and Its Impregnation with Quercetin Using Supercritical $\mathrm{CO}_{2}$
}

\author{
Ignacio García-Casas $\mathbb{D}$, Antonio Montes *, Diego Valor, Clara Pereyra $\mathbb{D}^{\mathbb{D}}$ and \\ Enrique J. Martínez de la Ossa \\ Department of Chemical Engineering and Food Technology, Faculty of Science, University of Cádiz, \\ International Excellence Agrifood Campus (CeiA3), 11510 Puerto Real (Cádiz), Spain \\ * Correspondence: antonio.montes@uca.es
}

Received: 16 July 2019; Accepted: 14 August 2019; Published: 23 August 2019

check for updates

\begin{abstract}
Foamed polycaprolactone impregnated with quercetin was carried out with a batch foaming technique using supercritical $\mathrm{CO}_{2}$. The experimental design was developed to study the influence of pressure (15-30 MPa), temperature (308-333 K), and depressurization rate (0.1-20) on the foam structure, melting temperature, and release tests of composites. The characterization of the experiments was carried out using scanning electron microscopy, X-ray diffractometer, and differential scanning calorimetry techniques. It was observed that the porosity created in the polymer had a heterogeneous structure, as well as the impregnation of the quercetin during the process. On the other hand, controlled release tests showed a significant delay in the release of quercetin compared to commercial quercetin.
\end{abstract}

Keywords: supercritical $\mathrm{CO}_{2}$; polycaprolactone; quercetin; foaming; impregnation; release profile

\section{Introduction}

The use of $\mathrm{CO}_{2}$ as a blowing agent in foaming has become increasingly popular in the scientific community to encapsulate, fabricate scaffolds, and produce delivery-controlled systems. This is due to the fact of $\mathrm{CO}_{2}$ 's properties as non-toxic, inexpensive, and reusable, as well as its high dissolution in polymers [1].

The supercritical foaming process has certain advantages; for example, the use of $\mathrm{CO}_{2}$ over other blowing agents, such as chlorofluorocarbon (CSF) or the non-use of co-solvent, make this technique an environmentally friendly process. This process exploits the compressibility power of $\mathrm{CO}_{2}$ on the polymer to create a porous structure in the polymer. Initially, the polymer is saturated with a gas at constant conditions of pressure and temperature. Once saturated, the system is driven (i.e., quenched) to a supersaturated state, usually decreasing the pressure, although if the process has been taken to low temperatures, the temperature could be increased. This causes nucleation and growth of the porous cells within the polymeric matrix [2]. There are different aspects to consider when a polymer is under supercritical conditions, such as the swelling, the melting point variation, and foaming [3-5]. Particularly in the case of semi-crystalline polymers, when the $\mathrm{CO}_{2}$ molecules are dissolved, they facilitate the mobility of the chains. This favors the reorganization of the polymer chains, lowering the crystallization temperature and improving crystallinity [6]. In the case of the effect caused by swelling in the matrix, this leads the polymer chains to reorganize into a more extended configuration. All this causes a greater facility in the formation of crystalline structures and, therefore, it usually decreases the melting temperature [7].

Polycaprolactone (PCL) is a semi-crystalline polyester with a melting point $\left(T_{\mathrm{m}}\right)$ of 329-334 K and a glass transition temperature $\left(T_{\mathrm{g}}\right)$ of $213 \mathrm{~K}$ [8]. Many studies have investigated the effect of pressure, temperature, time, and, to a lesser extent, the depressurization rate on the foaming and 
impregnation processes [3,9-11] of PCL with supercritical $\mathrm{CO}_{2}\left(\mathrm{scCO}_{2}\right)$. Several studies have reported that a polymer could be impregnated by an active substance by a swelling process when $\mathrm{scCO}_{2}$ is vented. Since the lower diffusivity of the active substance regarding to the $\mathrm{scCO}_{2}$, it can be trapped by the polymeric matrix $[3,12]$. This fact provokes the idea that the foaming and impregnation processes happen during a one-step process. Growth factors were impregnated into hybrid PCL-starch scaffolds to study its delivery [13]: dexamethasone was impregnated into PCL/silica nanoparticles [14] and into silk fibroin aerogel/PCL for bone regeneration [15], nimesulid was impregnated into PCL via a one-step foaming/impregnation process [16], strontium was impregnated into PCL scaffolds [17], and $\mathrm{TiO}_{2}$ was impregnated into PCL for removal textile dyes [18]. Even Tsivintzelis et al. [19] reported the use of co-solvent (ethanol) in the formation of more homogenous scaffolds with PCL.

Quercetin $(Q)$ is a flavonoid present in many fruits and vegetables [20]. This flavonoid is highlighted for its antioxidant action, but it has different benefits such as anti-inflammatory, antibacterial, cardiovascular health, and anticancer effects [21,22]. This antioxidant compound has been used by several authors with $\mathrm{scCO}_{2}$ in addition to different supercritical techniques, such as a supercritical antisolvent process to co-precipitate or encapsulate the quercetin with polymer [23,24] and a supercritical impregnation process (SSI) to impregnate the quercetin into different polymers or a porous matrix [25,26]. The SSI processes substitutes the liquid organic solvent with a supercritical fluid giving it the advantage that the final product is completely free of any residual solvent contamination. Thus, controlled quercetin release could be prepared as a safe process.

This paper focused on the use of a biodegradable polymer PCL as a coating agent for a delivery system to control the release of an active substance. In this article, a one-step foaming/impregnation process with PCL and quercetin was conducted. Moreover, the effect of pressure, temperature, and depressurization rate on the foaming process, the melting temperature and melting heat of the composites, and on the release profiles of quercetin were evaluated.

\section{Materials and Methods}

\subsection{Materials}

Polycaprolactone (pellets, average $M_{n} 45.000 \mathrm{~g} \mathrm{~mol}^{-1}$ ) was provided by Sigma-Aldrich (Madrid, Spain). Quercetin $\left(\mathrm{C}_{15} \mathrm{H}_{10} \mathrm{O}_{7}\right)$ was purchased from Sigma-Aldrich (Madrid, Spain). $\mathrm{CO}_{2}$ with a minimum purity of $99.8 \%$ was supplied by Linde (Barcelona, Spain).

\subsection{Experimental Design}

A design of experiment (DOE) was carried out in order to identify the main factors that should be taken into account in the foamed PCL-quercetin preparation using supercritical $\mathrm{CO}_{2}$. A full factorial design $2^{3}$ was performed. The complete design consisted of 11 experimental points that included 8 factor points and three replications at the center point (experiments 1,2 and 8). The main factors were selected with adequate ranges for this design. The responses of the design were melting temperature $\left(T_{\mathrm{m}}\right), \mathrm{mg}$ of released quercetin with regard to $\mathrm{g}$ of $\mathrm{PCL}$, and melting heat $\left(H_{\mathrm{m}}\right)$. The design was conducted with Modde 5.0 software.

Pressure $(P)$, temperature $(T)$, and depressurization rate $\left(D_{\mathrm{r}}\right)$ were identified as the main factors that can directly influence the foaming process of the features of the formed composites and, thus, on quercetin release profiles. The two levels for each factor are shown in Table 1. The levels of pressure and temperature were selected to evaluate the influence of different supercritical $\mathrm{CO}_{2}$ densities on the achievement of different degrees of plasticization of the polymer in including quercetin into its structure. Depressurization rate levels were selected according to the minimum and maximum set points available from the equipment supplier. The contact times were fixed to $1 \mathrm{~h}$ in order to ensure that there was enough time to form a polymer plasticization and to keep the costs reasonable. 
Table 1. Two-level assessment for each factor and the calculated effects on responses.

\begin{tabular}{cccccc}
\hline Factors & Low Level & High Level & $\begin{array}{c}\boldsymbol{T}_{\mathbf{m}} \\
\text { Effects }\end{array}$ & $\begin{array}{c}\text { Released } \boldsymbol{Q} \\
\text { Effects }\end{array}$ & $\begin{array}{c}\boldsymbol{H}_{\boldsymbol{m}} \\
\text { Effects }\end{array}$ \\
\hline$P(\mathrm{MPa})$ & 15 & 30 & -0.44 & 0.59 & -0.61 \\
$T(\mathrm{~K})$ & 308 & 333 & -2.02 & 0.90 & -1.90 \\
$\left.\operatorname{Dr}(\mathrm{MPa} \mathrm{min})^{-1}\right)$ & 0.10 & 20 & 1.31 & -0.75 & 1.42 \\
\hline
\end{tabular}

\subsection{Foaming and Impregnation with $\mathrm{scCO}_{2}$}

The experimental setup of the apparatus used to foam and impregnate is represented in Figure 1. The plant consisted of a $\mathrm{CO}_{2}$ bottle, a high-pressure pump to boost the $\mathrm{CO}_{2}$, a thermal bath to cool the $\mathrm{CO}_{2}$ to its liquid state, a heat exchanger to fix the temperature, a stainless-steel cell with a volume of $257 \mathrm{~mL}$ where the foaming and impregnation was carried out. Initially, each sample was formed by $500 \mathrm{mg}$ of PCL and $10 \mathrm{mg}$ of quercetin mixed physically into an aluminum foil support (ratio 50:1 PCL:Q). Then, it was introduced into a stainless-steel cell, after which $\mathrm{CO}_{2}$ was pumped into the cell to reach the optimum conditions for the foaming process at the same time that the temperature was adjusted. This study was carried out in the range of 15-30 MPa of pressure, temperatures of 308-333 K, and a foaming/impregnation time of $1 \mathrm{~h}$. Once the process time had finished, the output valve was

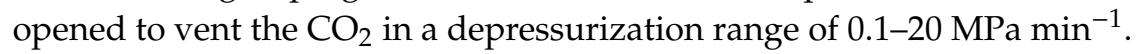

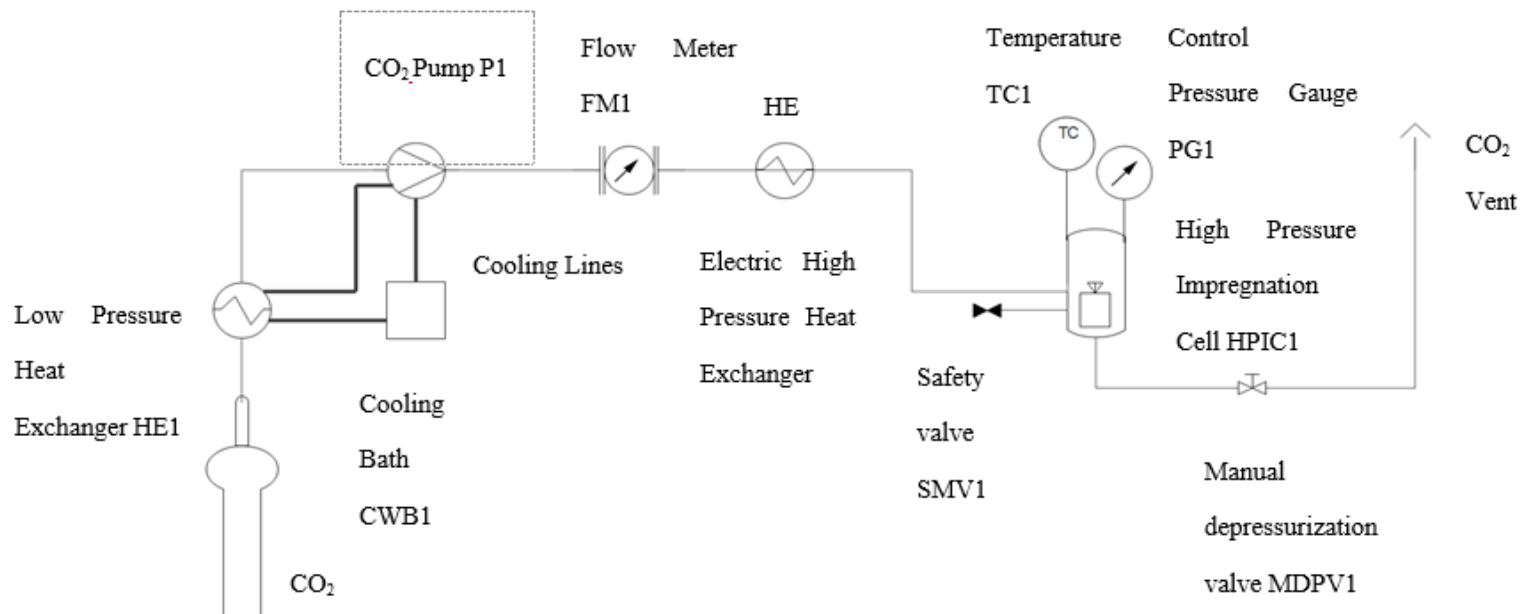

Figure 1. Schematic foaming/impregnation plant.

\subsection{Sample Characterization}

\subsubsection{Scanning Electron Microscopy}

Foamed/impregnated polymer samples were processed with a FEI TENEO scanning electron microscope (SEM) in order to analyze morphology. The images were obtained on a cross-section of the sample on a carbon tape and then coated with a $12 \mathrm{~nm}$ film of gold prior to analysis.

\subsubsection{X-Ray Diffraction}

X-ray diffraction (XRD) analysis was performed on a Bruker D8 Advance diffractometer in order to determine the amorphous or crystalline nature of the foamed polymer loaded with quercetin after the supercritical foaming/impregnation process. All diffraction patterns were scanned from $10^{\circ}$ to $50^{\circ}$ in $2 \theta$ angles with a step size of $0.02^{\circ}$ and $1 \mathrm{~s}$ as the step time. $\mathrm{CoK}_{\mathrm{a}}$ was the used source. 


\subsubsection{Differential Scanning Calorimetry}

Thermal property measurements were taken with a DSC Q100 (TA Instruments). Samples were heated to $373 \mathrm{~K}$ at a heating rate of $10 \mathrm{~K} \mathrm{~min}^{-1}$, then samples were cooled at $10 \mathrm{~K} \mathrm{~min}^{-1}$, and finally heated to $373 \mathrm{~K}$ at the same rate. All tests were carried out under the protection of a nitrogen $(99.999 \%)$ atmosphere and following the standards for DSC, ISO 11357-3 [2018].

\subsection{In Vitro Release Test}

Simulated fluid (SF) was produced in the laboratory, which was a solution of $6.8 \mathrm{~g} / \mathrm{L}$ of monobasic potassium phosphate in distilled water and adjusted to $\mathrm{pH} 6.8 \pm 0.1$ with $0.2 \mathrm{~N} \mathrm{NaOH}$.

An amount of $0.25 \mathrm{~g}$ of the polymer impregnated with quercetin was dissolved in $40 \mathrm{~mL}$ of SF in order to carry out the release test. The release tests were carried out at a temperature of $310 \mathrm{~K}$ and a stirring speed of $165 \mathrm{rpm}$, and $3 \mathrm{~mL}$ aliquots were withdrawn and filtered at time intervals of 5,15 , 30, $60 \mathrm{~min}$, and then every hour until $480 \mathrm{~min}$. Finally, an extra aliquot was withdrawn after $24 \mathrm{~h}$. The released quercetin was measured with a Shimadzu UV-VIS mini spectrophotometer at $\lambda=365$. The calculation was based on that reported by Zhu et al. [27] to calculate correctly the concentration of released quercetin.

\section{Results and Discussion}

\subsection{Analysis of the Design of Experiments}

The values for the coefficient of determination $R^{2}$ (goodness of fit), $Q^{2}$ (goodness of prediction), degree of freedom $(D F)$, sum of squares (SS), and mean square (MS) are shown in Table 2. According to $R^{2}$, the model was well adjusted and the goodness of prediction $\left(Q^{2}\right)$ was good for $T_{\mathrm{m}}$ and $\mathrm{mg}$ of released $Q$. However, $H_{\mathrm{m}}$ was badly adjusted, thus, no conclusions can be established from the model for this response. Analyzing the values of $F$ and $p$ (a high $F$-value and a low $p$-value less than 0.05 ), it can be ensured that the model was significant for the two first responses [28], but not significant for $H_{\mathrm{m}}$. It can be seen from Table 2 that, statistically, the model's lack of fit was due to the probability of a lack of fit being non-significant at $95 \%$. The experimental design and the responses of the experiments are provided in Table 3.

The effects on responses had positive and negative signs, as can be seen in Table 1 . The sign of each effect indicates whether the response increased or decreased when the experiments changed from a low to a high level. For instance, an increase in temperature from low to high led to a considerable decrease in $T_{\mathrm{m}}$. Depressurization rate had the second most marked effect on $T_{\mathrm{m}}$ but, in this case, the trend was the opposite: an increase in $D_{\mathrm{r}}$ led to an increase in $T_{\mathrm{m}}$. With regard to the released quercetin, the most marked effect was observed for temperature followed by $D_{\mathrm{r}}$ and pressure but, in this case, the effect's difference was lower. These effects had different signs, which indicate that released quercetin increased with pressure and temperature and decreased with $D_{\mathrm{r}}$.

Taking into account the calculated effects in Table $1, H_{\mathrm{m}}$ decreased when pressure and temperature decreased and increased when $D_{\mathrm{r}}$ decreased. However, according to Table 2, no significant difference in $H_{\mathrm{m}}$ was found and it was not possible to establish any trends.

Coefficients of the linear model for the significant responses, $T_{\mathrm{m}}$ and released quercetin given in Table 4 show that temperature and $D_{\mathrm{r}}$ were the main significant variables for both responses $(p<0.05)$. 
Table 2. Analysis of variance for the design model of process variables.

\begin{tabular}{|c|c|c|c|c|c|c|c|c|c|}
\hline Variables & & $D F$ & $S S$ & MS & $R^{2}$ & $A d j R^{2}$ & $Q^{2}$ & $\begin{array}{c}\text { Significance } \\
F\end{array}$ & $\begin{array}{c}\text { Lack of Fit } \\
p\end{array}$ \\
\hline \multirow[t]{3}{*}{$T_{m}$} & Model & 9 & 16.86 & 1.87 & 0.95 & 0.84 & 0.53 & 8.72 & 0.048 \\
\hline & Residual & 3 & 0.91 & 0.30 & & & & & \\
\hline & Error & 2 & 0.85 & 0.42 & & & & & \\
\hline \multirow[t]{3}{*}{ Released $Q$} & Model & 9 & 4.17 & 0.46 & 0.95 & 0.84 & 0.57 & 9.08 & 0.049 \\
\hline & Residual & 3 & 0.22 & 0.07 & & & & & \\
\hline & Error & 2 & 0.12 & 0.06 & & & & & \\
\hline \multirow[t]{3}{*}{$H_{m}$} & Model & 9 & 379.17 & 42.13 & 0.49 & -0.52 & 0.04 & 0.48 & 0.79 \\
\hline & Residual & 3 & 191.68 & 63.90 & & & & & \\
\hline & Error & 2 & 88.78 & 44.40 & & & & & \\
\hline
\end{tabular}

\subsection{Foaming and Impregnation Experiments}

All experiments showed visually an inhomogeneous impregnation along the structure of the PLC, as can be seen in Figure 2. The bottom of the polymers seemed to accumulate the highest quantity of $Q$. The low solubility of $Q$ in $\mathrm{scCO}_{2}$ [29] may have contributed to the higher amounts of $Q$ found at the bottoms. Experiments 5 and 10, conducted at the maximum temperature $(333 \mathrm{~K})$ and at the lowest depressurization rate $(0.1 \mathrm{MPa})$ but with different pressures (15 and $30 \mathrm{MPa}$, respectively), showed the same external texture, presenting the highest foaming effect. Furthermore, experiments 3 , 4,7 , and 11 exhibited the lowest foaming effect. These experiments were carried out at the minimum level of temperature $(308 \mathrm{~K})$ revealing the importance of temperature in the foaming process. Finally, experiments 6 and 9, conducted at the maximum temperature $(333 \mathrm{~K})$ and the fastest depressurization rate $(0.1 \mathrm{MPa})$, exhibited a similar aspects to experiments 1,2 , and 8 (central point experiments at $22.5 \mathrm{MPa}, 320.5 \mathrm{~K}$ and $2.5 \mathrm{MPa} \mathrm{min}^{-1}$ ) with foaming, a surface formed by small bubbles and a lower volume than experiments 5 and 10 .

Table 3. Experimental design and observed responses.

\begin{tabular}{ccccccc}
\hline Experiments & $\begin{array}{c}\boldsymbol{P} \\
\mathbf{M P a})\end{array}$ & $\begin{array}{c}\boldsymbol{T} \\
\mathbf{( K )}\end{array}$ & $\begin{array}{c}\boldsymbol{D}_{\boldsymbol{r}} \\
\left(\mathbf{M P a} \mathbf{~ m i n}^{-\mathbf{1}}\right)\end{array}$ & $\boldsymbol{T}_{\boldsymbol{m}} \mathbf{( K )}$ & $\begin{array}{c}\text { mg Released } \\
\mathbf{Q / g} \mathbf{P C L}\end{array}$ & $\boldsymbol{H}_{\boldsymbol{m}}(\mathbf{J} / \mathbf{g})$ \\
\hline 1 & 22.5 & 320.5 & 2.5 & 334.70 & 4.63 & 85.07 \\
2 & 22.5 & 320.5 & 2.5 & 333.63 & 4.33 & 73.50 \\
3 & 30 & 308 & 20 & 336.70 & 3.35 & 87.39 \\
4 & 15 & 308 & 20 & 337.10 & 3.22 & 83.69 \\
5 & 30 & 333 & 0.1 & 333.48 & 5.36 & 90.58 \\
6 & 15 & 333 & 20 & 333.91 & 3.58 & 87.77 \\
7 & 15 & 308 & 0.1 & 338.32 & 3.35 & 84.57 \\
8 & 22.5 & 320.5 & 2.5 & 334.81 & 4.14 & 85.01 \\
9 & 30 & 333 & 20 & 333.23 & 4.91 & 96.52 \\
10 & 15 & 333 & 0.1 & 333.61 & 4.40 & 80.10 \\
11 & 30 & 308 & 0.1 & 333.74 & 4.10 & 92.69 \\
\hline
\end{tabular}

Table 4. Coefficients list of the linear model for $T_{\mathrm{m}}$ and released quercetin and their significance.

\begin{tabular}{ccccc}
\hline & Coefficient $\left(T_{m}\right)$ & $p\left(T_{m}\right)$ & $\begin{array}{c}\text { Coefficient } \\
\text { (Released } Q)\end{array}$ & $p$ (Released $Q)$ \\
\hline Constant & 61.40 & $6.26 \times 10^{-8}$ & 4.25 & $2.18 \times 10^{-5}$ \\
$P$ & -0.19 & 0.43 & 0.26 & 0.08 \\
$T$ & -0.88 & 0.02 & 0.39 & 0.03 \\
$D r$ & 0.57 & 0.04 & -0.33 & 0.04 \\
$P \cdot T$ & $-5.71 \times 10^{-3}$ & 0.98 & 0.23 & 0.09 \\
$P D r$ & -0.04 & 0.86 & 0.06 & 0.55 \\
$T \cdot D r$ & -0.57 & 0.06 & 0.05 & 0.62 \\
\hline
\end{tabular}



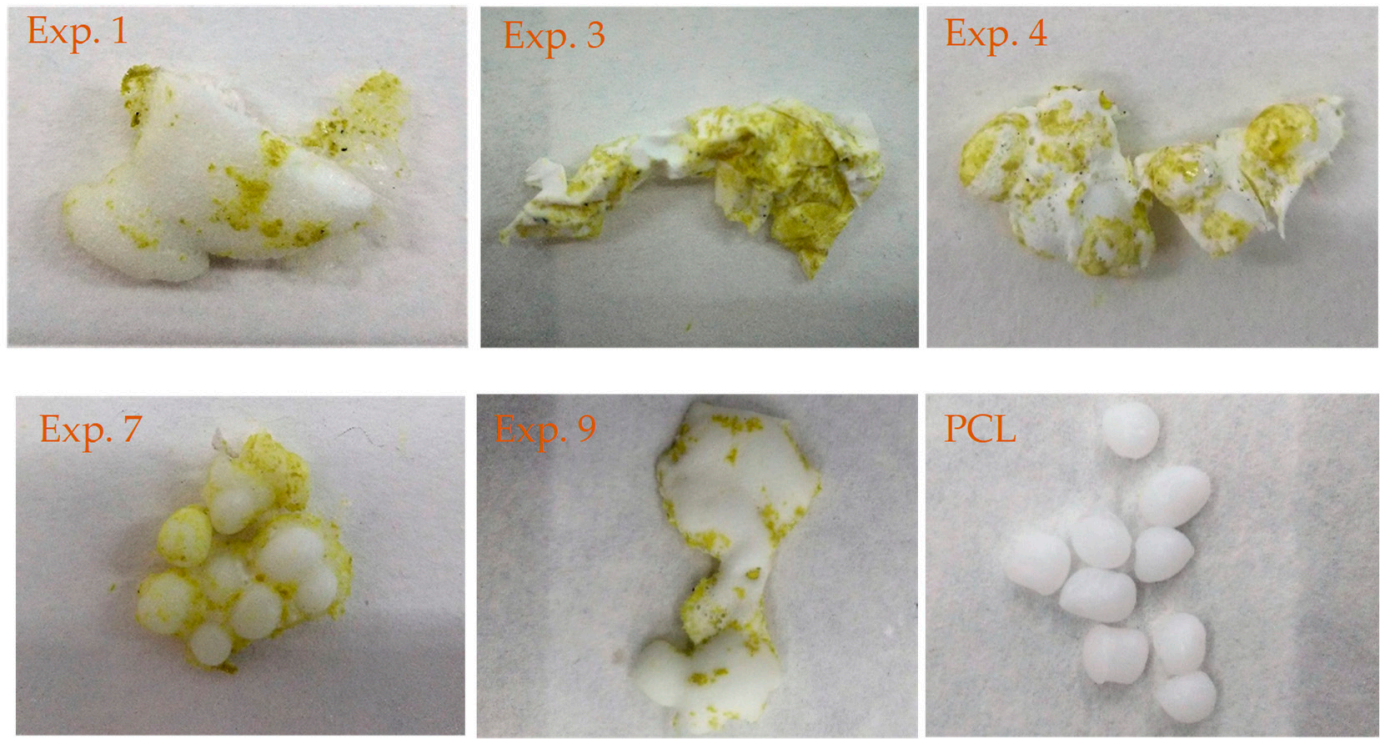

Figure 2. Photos of experiments 1, 3, 4, 7, and 9 and raw PCL.

\subsection{Characterization}

\subsubsection{Scanning Electron Microscope (SEM)}

The experiments conducted were screened with SEM (Figure 3). Raw PCL was also analyzed in order to compare possible changes in the porosity structure. Unlike raw PCL, the images of the composites show the formation of unstructured porous structures due to the adsorption of $\mathrm{scCO}_{2}$ into the semi-crystalline polymer, and the subsequent heterogeneous nucleation at the interface between the crystalline and amorphous regions and the homogeneous nucleation in the amorphous phase [30]. A structural difference depending on the depressurization rate was observed. Experiments 5, 7, 10, and 11 (Figure 3), carried out at a low depressurization rate $\left(0.1 \mathrm{MPa} \mathrm{min}^{-1}\right)$, present a surface with big pores (around $100 \mu \mathrm{m}$ ) and lower cell number densities. However, the experiments 3, 4, 6, and 9 (Figure 3), conducted at a fast depressurization rate $\left(20 \mathrm{MPa} \mathrm{min}^{-1}\right)$, showed a high presence of micro and nano pores with higher cell number densities. Given the impact of pressure and temperature, experiments 3 and 4 had the higher density of pores, with an abundance of pores on the surface area, as can be seen in Figure 3. This was expected because experiments 3 and 4 were carried out at a lower temperature than experiments 6 and 9 (from 333 to $308 \mathrm{~K}$ ). Particular attention should be paid to experiment 3 , carried out at a higher pressure (30 MPa) and at the same temperature $(308 \mathrm{~K})$ and depressurization rate $\left(20 \mathrm{Mpa} \mathrm{min}^{-1}\right)$, where a higher cell density can be observed. It is known $[3,19,31]$ that the solubility of $\mathrm{CO}_{2}$ in the polymer increases when the temperature decreases and pressure increases; this causes an increase in the amount of $\mathrm{CO}_{2}$ in the PCL, causing higher cell density and smaller cell diameter. Also, the nucleation theory [2] explains that, at higher temperatures and lower pressures, the energy barrier to nucleation increases; consequently, the generation of nuclei is rougher, causing the reduction in the final cell density. 

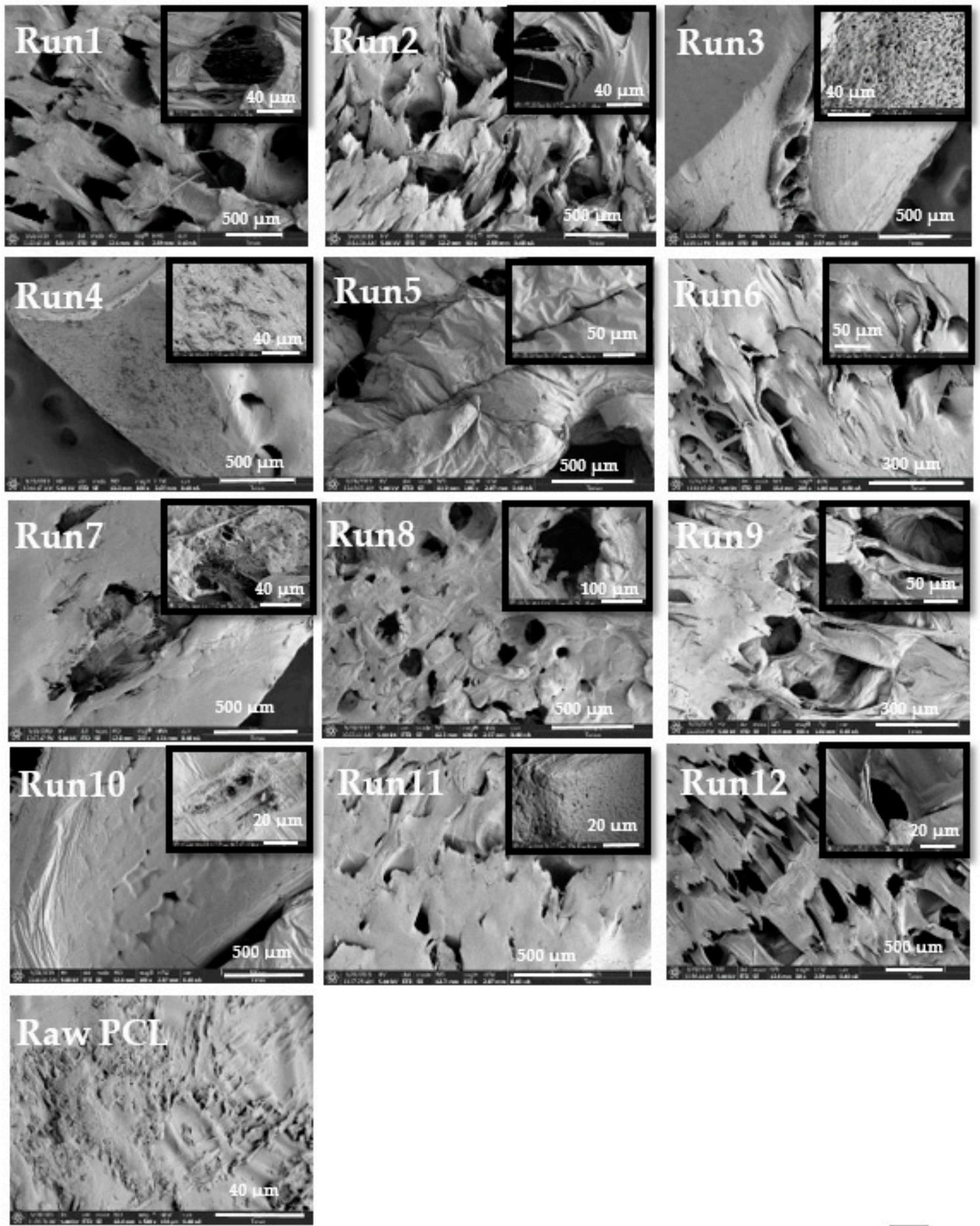

Figure 3. SEM images of composites and raw PCL.

\subsubsection{X-ray Diffraction}

The XRD analysis (Figure 4 and Supplementary Materials) shows all experiments with a typical XRD diffraction pattern of raw PCL, and the same pattern for the treated PCL and foamed/impregnated samples. The PCL is a semi-crystalline polymer with peaks of high intensity at $21.25^{\circ}$ and $23.7^{\circ}$. The supercritical foaming process increases the intensity of the crystallinity peak and decreases the presence of quercetin, reducing its crystallinity. This occurs because the presence of quercetin blocks the formation of large crystallites [14,32]. The peak of raw $Q$ showed a wide quantity of characteristic 
peaks situated at $2 \theta=12.3^{\circ}, 12.9^{\circ}, 17.75^{\circ}, 21.95^{\circ}, 24.5^{\circ}, 26.5^{\circ}$, and $27.4^{\circ}[22,33]$. Comparing the PCL foamed/impregnated diffraction patterns with the quercetin diffraction pattern (Figure 4), it is observed that the peaks of raw $Q$ are not presented. It could be due to the fact that $Q$ was changed to an amorphous nature, although this seems to be unlikely. Thus, it was probably caused due to the inhomogeneous impregnation of quercetin or the quite higher ratio polymer: quercetin.

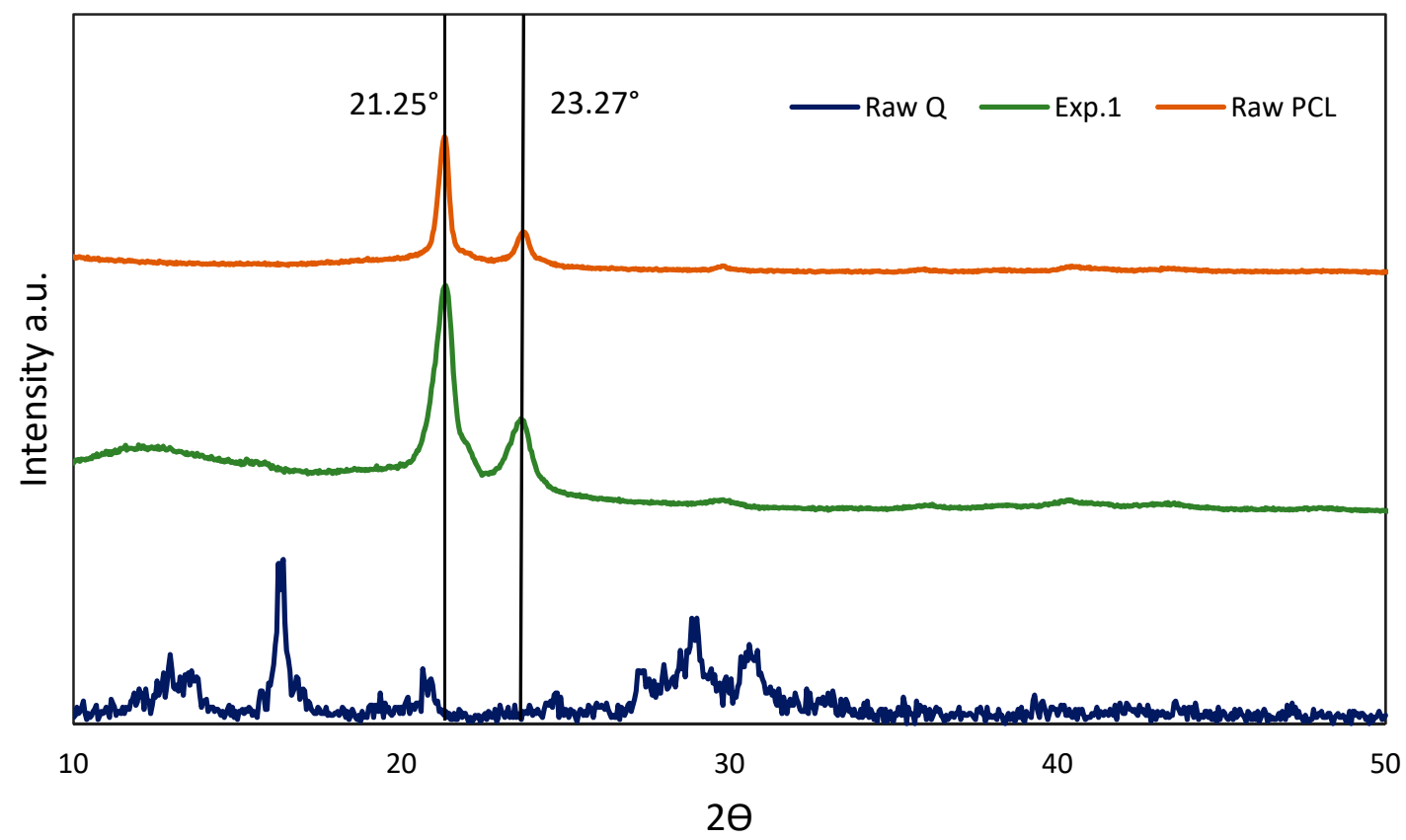

Figure 4. XRD diffraction pattern of composites, raw $Q$ and PCL.

\subsubsection{Differential Scanning Calorimetry}

Figure 5 represents the DSC analyses of the samples, which are more different. In every plot, a simple peak corresponding to the melting temperature is shown. Moreover, melting heat $\left(H_{\mathrm{m}}\right)$ was proportioned by DSC. Both $T_{\mathrm{m}}$ and $H_{\mathrm{m}}$ are collected in Table 3. In general, it must be taken into account that the pressurization of $\mathrm{CO}_{2}$ including quercetin leads to a polymer with a $T_{\mathrm{m}}$, in some cases, with eight degrees of difference. With regard to $H_{\mathrm{m}}$, it was not possible to establish parameter trends due to the statistical parameter collected in the ANOVA table, which pointed to quite bad adjustment and prediction (Table 3 ). Besides, the highest $H_{\mathrm{m}}$ was found when the highest values of pressure, temperature, and $D_{\mathrm{r}}$ were set (Experiment 9). In Figure 6, the main effect plots on $T_{\mathrm{m}}$ can be seen. An increase in temperature led to a composite with notably lower $T_{\mathrm{m}}$, and an increase in pressure had the same trend but with lower influence. This can be explained due to the fact that when higher operating conditions are set, $\mathrm{CO}_{2}$ is able to penetrate into the polymer chain where $Q$ can be located, leading to a less stable structure and, thus, lower $T_{\mathrm{m}}$. Moreover, the soaking of $\mathrm{CO}_{2}$ into the polymer structure improves the crystallinity and then decreases $T_{\mathrm{m}}[6,7]$. However, the depressurization rate had the opposite trend, so when $D_{\mathrm{r}}$ increased, composites with higher $T_{\mathrm{m}}$ formed. In the depressurization step, nucleation of the bubbles and diffusion of the $\mathrm{CO}_{2}$ through the polymer competed. At a rapid depressurization rate, more nuclei were formed and the growth and coalescence of pores were minimized before vitrification led to a more uniform pore size distribution $[34,35]$. This pore structure was related to the more thermal stability (higher $T_{\mathrm{m}}$ ) of composites according to the obtained results.

The nature of interaction among variables was also explored, as can be seen in Figure 7 where interaction plots are shown. In general, no interaction was observed between pressure and temperature and pressure and $D_{\mathrm{r}}$. It seems that only $D_{\mathrm{r}}$ and temperature had a mild interaction, so at a low level of temperature, $D_{\mathrm{r}}$ had a significant influence on $T_{\mathrm{m}}$, increasing when $D_{\mathrm{r}}$ was augmented. However, at a high temperature, the $D_{\mathrm{r}}$ effect was neglected. 


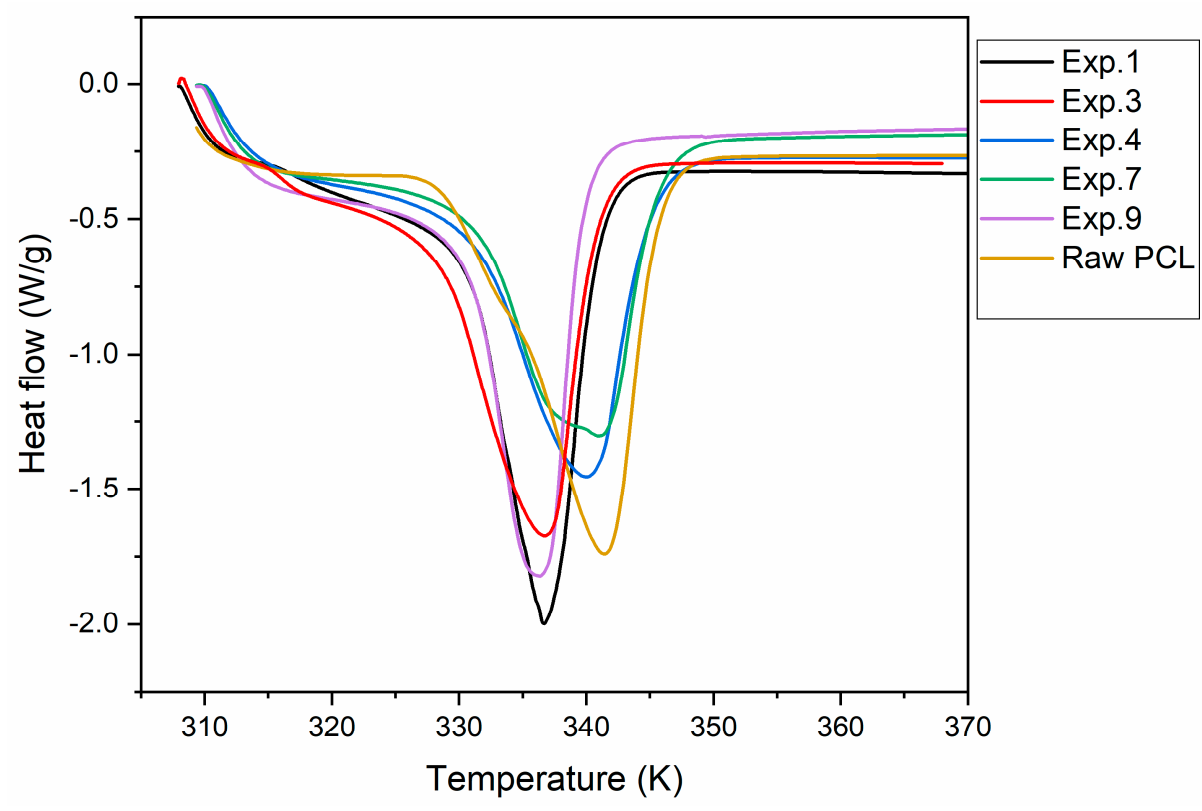

Figure 5. DSC diagrams of composite PCL-quercetin.
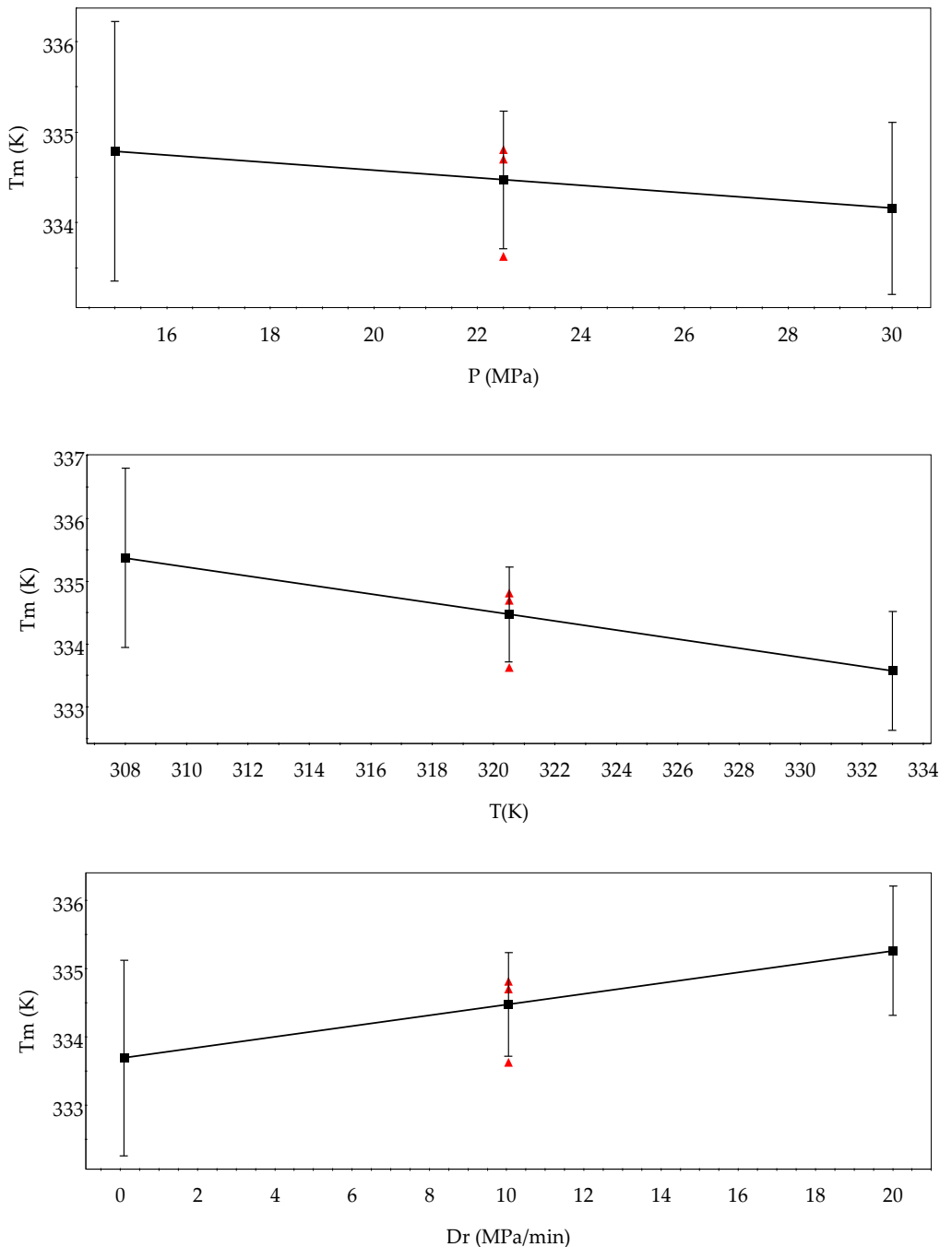

Figure 6. Main effects on $T_{\mathrm{m}}$ of composite PCL-quercetin. 
Two main effects plots are shown in Figure 8. The surface slope was made by two main effects and the possible twist by their two-factor interaction. The twist was observed as expected when $D_{\mathrm{r}}$ and temperature were plotted. In general, lower pressure and lower temperature together with higher $D_{\mathrm{r}}$ lead to composites with higher $T_{\mathrm{m}}$.
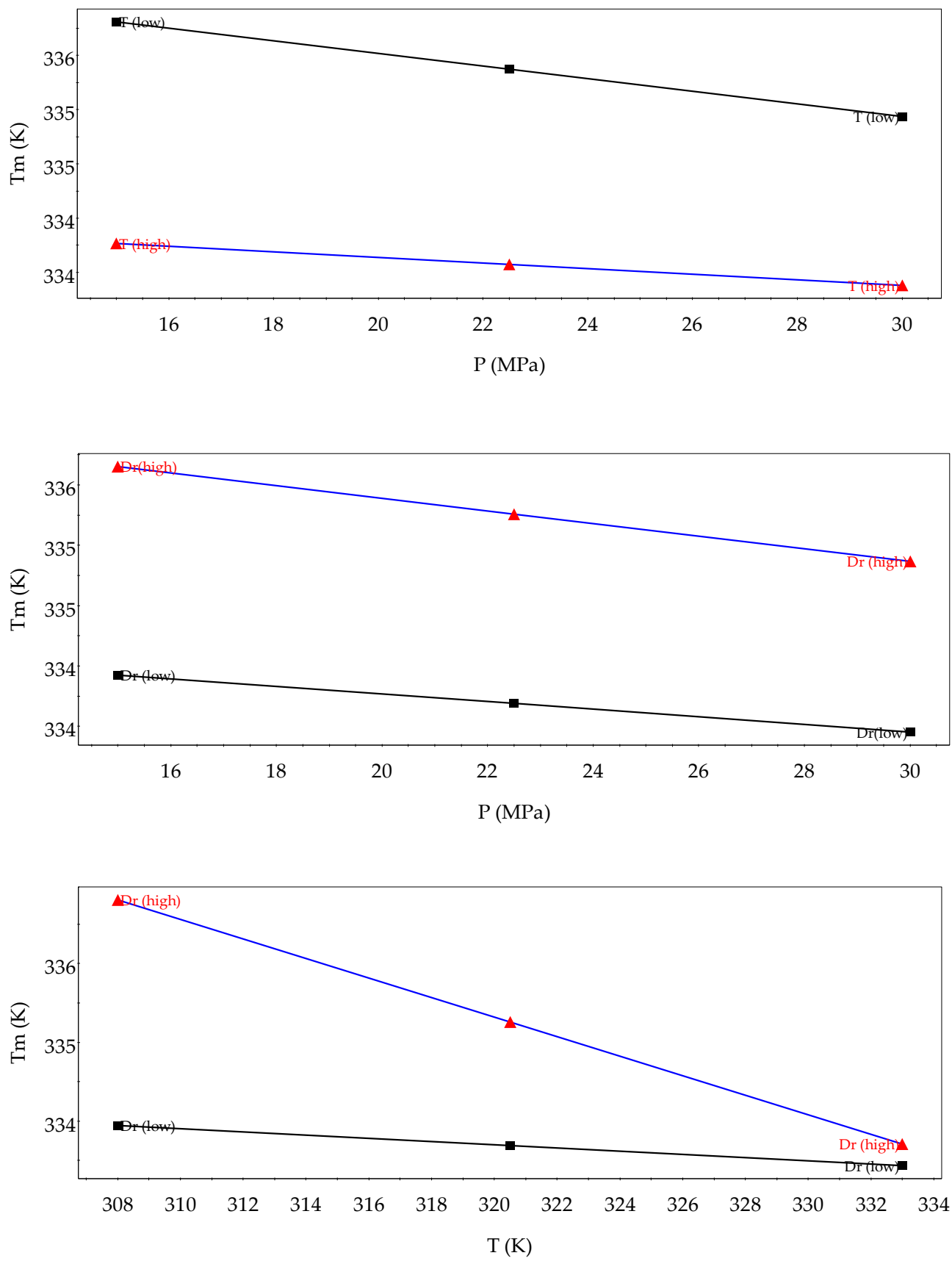

Figure 7. Variable interaction plots on $T_{\mathrm{m}}$ of composite PCL-quercetin. 

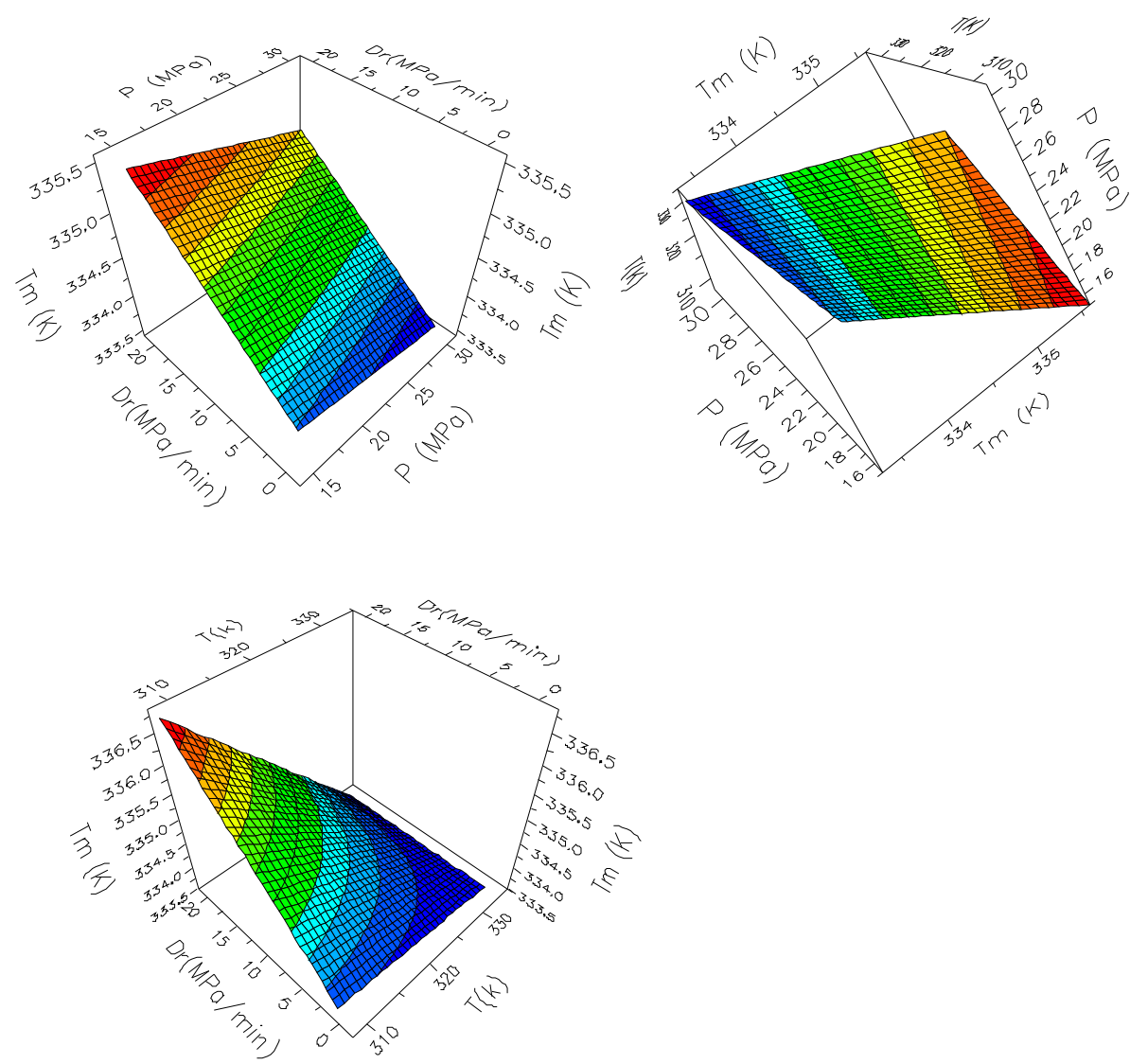

Figure 8. Response surface plots of $T_{\mathrm{m}}$ of composites.

\subsection{In Vitro Release Test}

The release of $Q$ from polymer was studied for all experiment (Figure 9a) and compared with raw quercetin (Figure 9b). In general, the release of $Q$ from polymer was slower than pure dissolution of quercetin alone. Release of $Q$ from polymer depends on the formed composites and, thus, on pressure, temperature, and $D_{\mathrm{r}}$. For instance, experiment 3 and 6 differed almost two times in mg of released $Q$. It is necessary to investigate the main effects, interactions, and response surface plots to shed light on the parameter influence on release profiles.

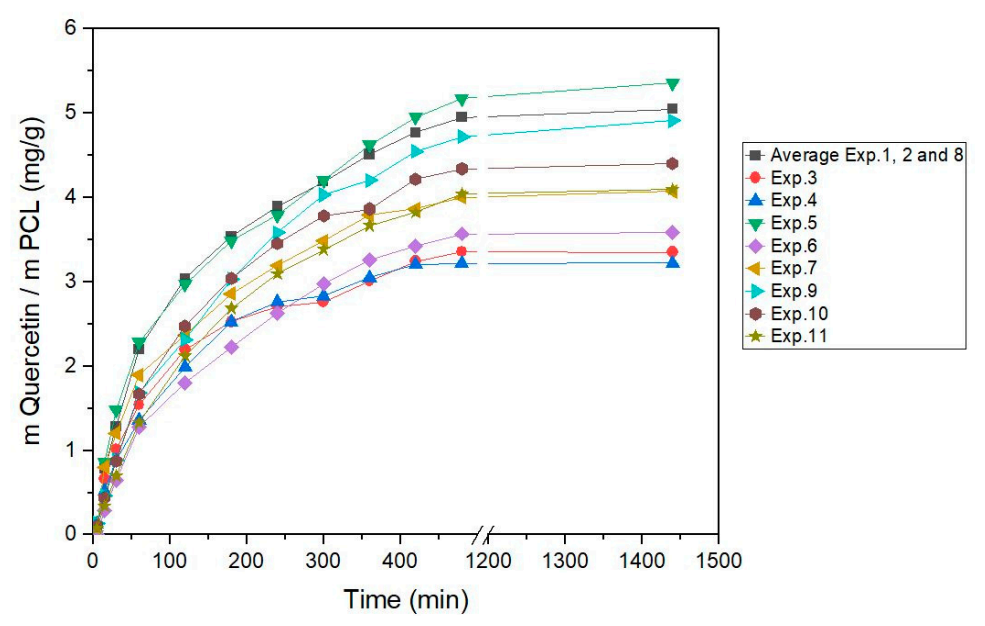

(a)

Figure 9. Cont. 


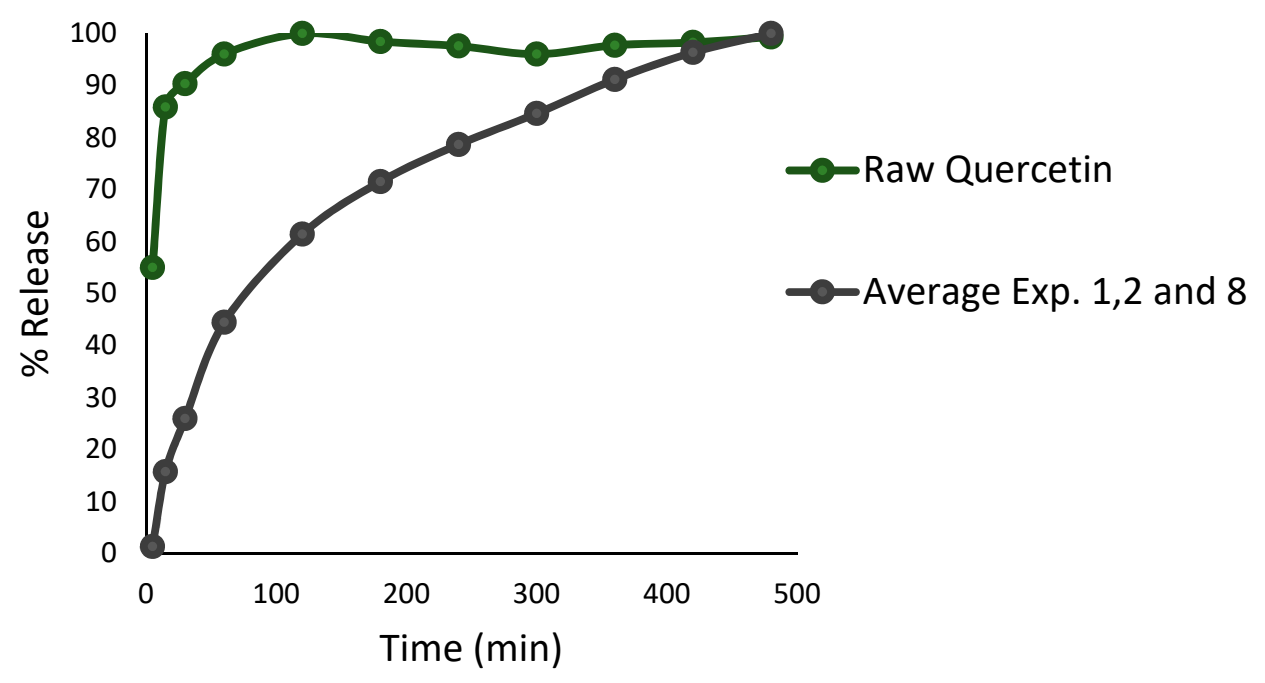

(b)

Figure 9. Release tests. (a) Release test of $Q$ with polymer in experiments $1-11$; (b) comparison release test raw $Q$ and average experiments 1,2 , and 8 .

In Figure 10, the main effect plots on released quercetin can be seen. An increase in pressure leads to a composite, where the $\mathrm{mg}$ of the released quercetin is increased. Temperature had the same trend due to the increase in cell diameter and lower cell density at a higher temperature process. In the same way, at higher conditions, $\mathrm{CO}_{2}$ penetrates more easily into the polymer structure increasing the space between polymer chains where quercetin can be located. In this sense, part of the quercetin would be more accessible and not entrapped in the rigid polymer structure to release into the media. However, $D_{\mathrm{r}}$ had the opposite trend, so an increase in $D_{\mathrm{r}}$ led to a lower amount of released quercetin. It was expected due to the fact that the samples obtained with higher $D_{\mathrm{r}}$ presented high densities of porosity in their surface areas and the sizes of the pores were smaller than in the other experiments.

All this supports that experiment 5 , with the higher pressure, temperature, and low depressurization rate $\left(30 \mathrm{MPa}, 333 \mathrm{~K}\right.$, and $\left.0.1 \mathrm{MPa} \mathrm{min}^{-1}\right)$, was the sample with the highest released $Q$ after 8 and $24 \mathrm{~h}$. Figure $9 \mathrm{~b}$ shows the release of raw $Q$ in comparison with experiment 1 , processes under the supercritical condition of $22.5 \mathrm{MPa}, 320.5 \mathrm{~K}$, and $2.5 \mathrm{MPa} \mathrm{min}^{-1}$. The release profile shows a significant difference; while the raw $Q$ needed $1 \mathrm{~h}$ to dissolve, the $Q$ impregnated in the foamed PCL needed $8 \mathrm{~h}$ to release and dissolve the same quantity of $Q$; this means it was eight times slower. This demonstrates the utility of PCL to coat an active principle, in this case $Q$, to control the release process for in vitro tests in simulated fluids with a $\mathrm{pH}$ around 7.

The nature of interaction among factors was also explored, as can be seen in Figure 11. In general, no interaction was observed between $D_{\mathrm{r}}$ and pressure and temperature. However, a mild interaction was observed between pressure and temperature, so at low pressure, the temperature effect was almost neglected on the released quercetin. This fact could be observed in the two main effects plots (Figure 12). It can be seen that higher pressure and temperature and lower $D_{\mathrm{r}}$ are recommended to release the highest amount of quercetin from the composites. 

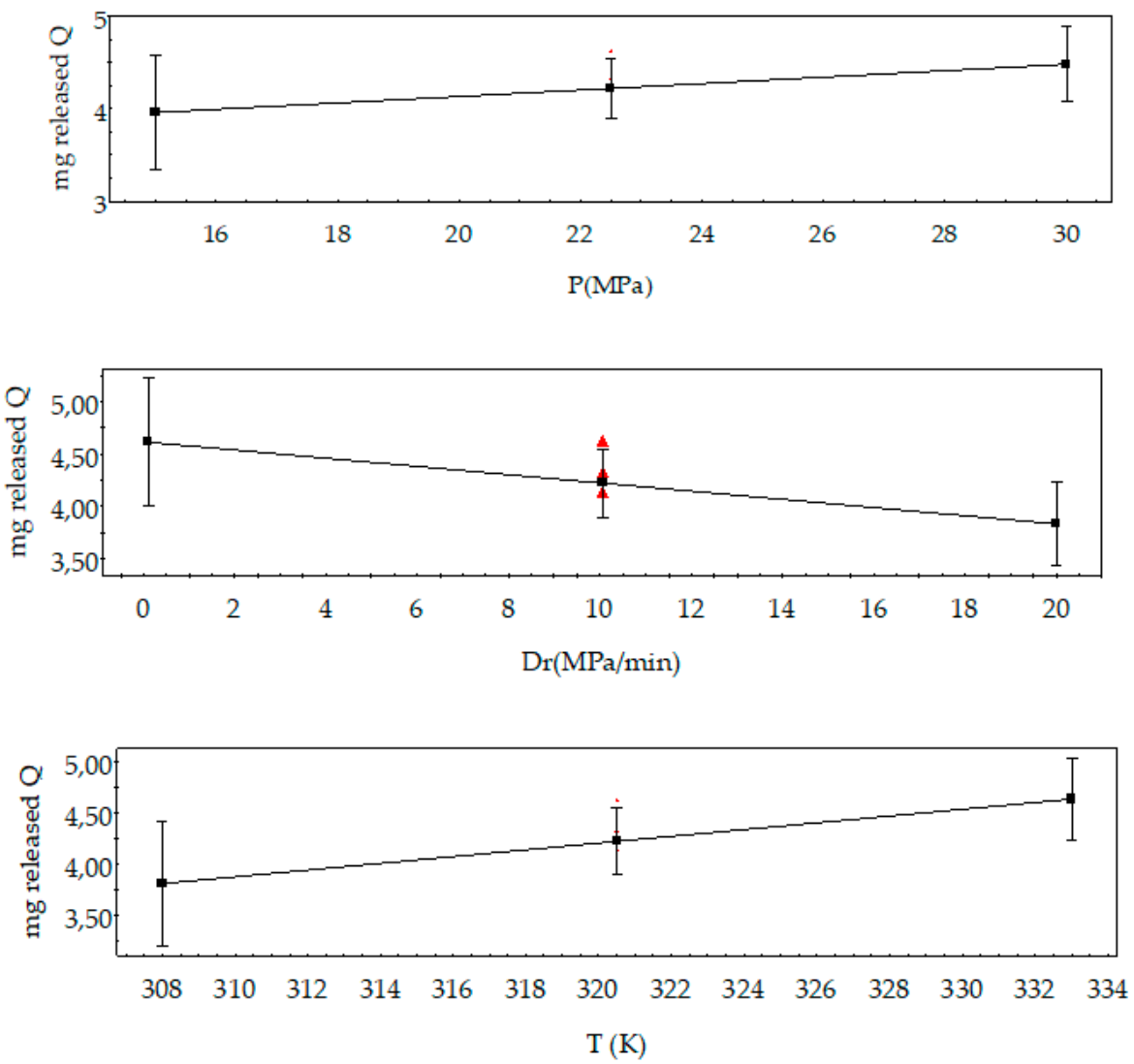

Figure 10. Main effects on released quercetin of the composites.
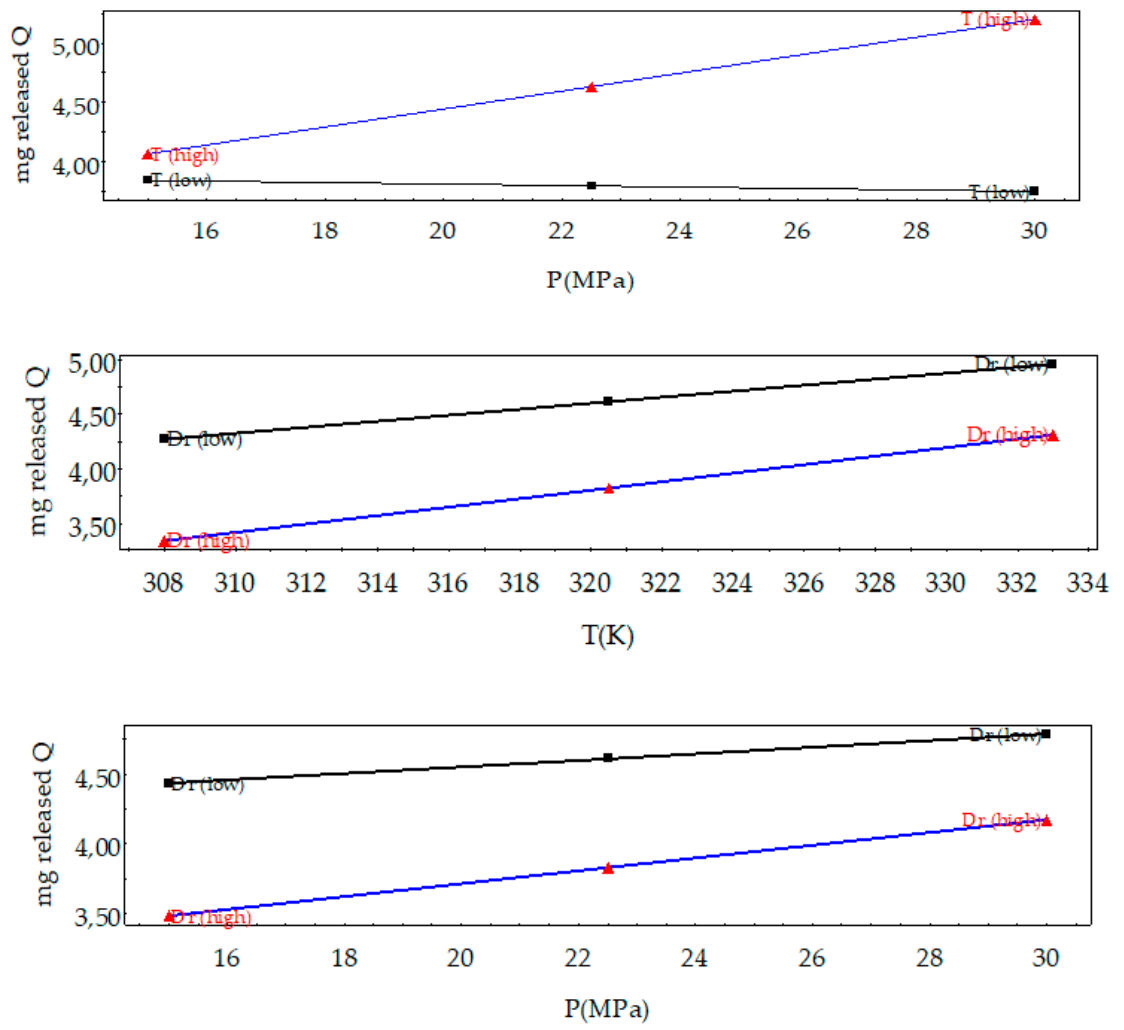

Figure 11. Variable interactions plots on released quercetin of the composites. 


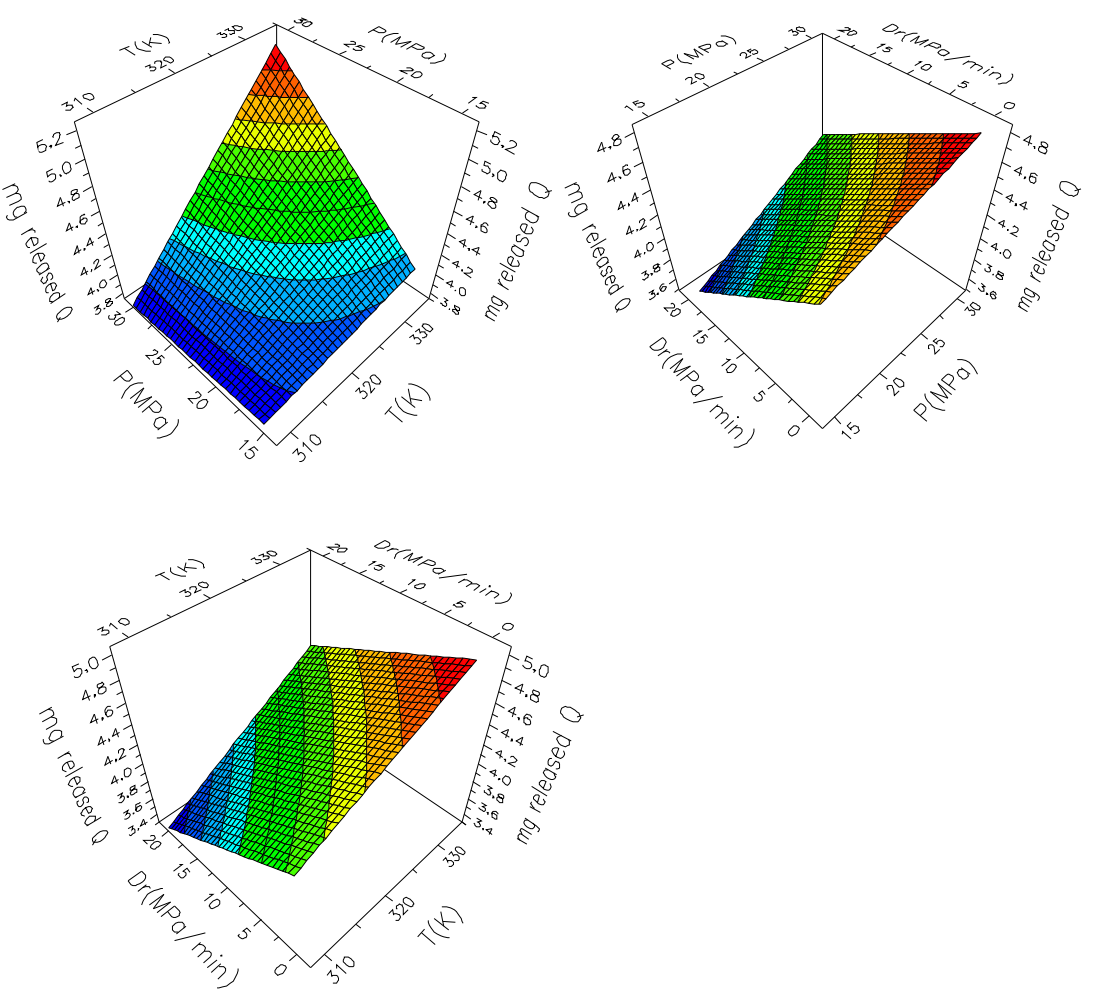

Figure 12. Response surface plots of released quercetin of the composites.

\section{Conclusions}

The foaming and impregnation one-step process of PCL and quercetin was successfully conducted. Pressure, temperature, and depressurization rate were evaluated for the foaming, melting temperature, melting heat, and the amount of released quercetin. Melting heat data had no significant differences and no trends were established. A high temperature is recommended to obtain a pronounced effect of foaming. Pressure and depressurization rate have an important influence on responses. The generated PCL/quercetin composites with higher pore density and smaller size were achieved for higher pressure

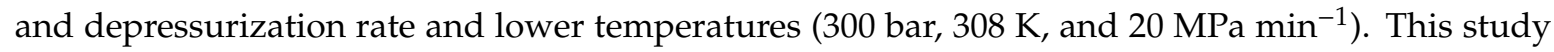
also showed that experiments carried out at lower pressure and temperature together with a higher depressurization rate lead to a higher melting temperature. An increase in pressure and temperature lead to a composite which releases higher amounts of quercetin. However, the depressurization rate had the opposite trend; thus, an increase in the depressurization rate led to lower amounts of released quercetin. Release profiles showed that quercetin takes five times longer to dissolve the same amount of quercetin in the first $8 \mathrm{~h}$, demonstrating the efficacy of using PCL to control quercetin release and its possible use with other medical or pharmaceutical compounds.

Supplementary Materials: The following are available online at http://www.mdpi.com/2073-4360/11/9/1390/s1. XRD patterns of experiments 1-11 and raw PCL.

Author Contributions: Investigation, I.G.-C. and D.V.; Methodology, A.M.; Project administration, E.J.M.d.l.O.; Supervision, C.P.

Funding: This research was funded by Ministerio de Ciencia y Tecnología: CTQ2017-86661-R and European Regional Development Funds: UNCA10-1E-1125 and 18INIA1103. 2011.

Acknowledgments: We gratefully acknowledge the Spanish Ministry of Science and Technology (Project CTQ2017-86661-R) and European Regional Development Funds (UNCA10-1E-1125 and 18INIA1103. 2011) for the financial support, and the Central Services of Science and Technology of University of Cádiz for the analyses.

Conflicts of Interest: The authors declare no conflict of interest. 


\section{References}

1. Kuang, T.; Chen, F.; Chang, L.; Zhao, Y.; Fu, D.; Gong, X.; Peng, X. Facile Preparation of Open-Cellular Porous Poly(L-lactic acid) Scaffold by Supercritical Carbon Dioxide Foaming for Potential Tissue Engineering Applications. Chem. Eng. J. 2017, 307, 1017-1025. [CrossRef]

2. Goel, S.K.; Beckman, E.J. Generation of Microcellular Polymeric Foams Using Supercritical Carbon Dioxide. II: Cell Growth and Skin Formation. Polym. Eng. Sci. 1994, 34, 1137-1147. [CrossRef]

3. Fanovich, M.A.; Jaeger, P. Sorption and Diffusion of Compressed Carbon Dioxide in Polycaprolactone for the Development of Porous Scaffolds. Mater. Sci. Eng. C 2012, 32, 961-968. [CrossRef]

4. Lian, Z.; Epstein, S.A.; Blenk, C.W.; Shine, A.D. Carbon Dioxide-Induced Melting Point Depression of Biodegradable Semicrystalline Polymers. J. Supercrit. Fluids 2006, 39, 107-117. [CrossRef]

5. Yoganathan, R.; Mammucari, R.; Foster, N.R. Impregnation of Ibuprofen into Polycaprolactone Using Supercritical Carbon Dioxide. J. Phys. Conf. Ser. 2010, 215, 6-11. [CrossRef]

6. Takada, M.; Hasegawa, S.; Ohshima, M. Crystallization Kinetics of Poly(L-lactide) in Contact with Pressurized $\mathrm{CO}_{2}$. Polym. Eng. Sci. 2004, 44, 186-196. [CrossRef]

7. Zhang, Z.; Handa, Y.P. $\mathrm{CO}_{2}$-Assisted Melting of Semicrystalline Polymers. Macromolecules 1997, 30, 8505-8507. [CrossRef]

8. Sinha, V.R.; Bansal, K.; Kaushik, R.; Kumria, R.; Trehan, A. Poly-€-Caprolactone Microspheres and Nanospheres: An Overview. Int. J. Pharm. 2004, 278, 1-23. [CrossRef]

9. Moghadam, M.Z.; Hassanajili, S.; Esmaeilzadeh, F.; Ayatollahi, M.; Ahmadi, M. Formation of Porous HPCL/LPCL/HA Scaffolds with Supercritical $\mathrm{CO}_{2}$ Gas Foaming Method. J. Mech. Behav. Biomed. Mater. 2017, 69, 115-127. [CrossRef]

10. Cotugno, S.; Di Maio, E.; Mensitieri, G.; Iannace, S.; Roberts, G.W.; Carbonell, R.G.; Hopfenberg, H.B. Characterization of Microcellular Biodegradable Polymeric Foams Produced from Supercritical Carbon Dioxide Solutions. Ind. Eng. Chem. Res. 2005, 44, 1795-1803. [CrossRef]

11. Xu, Q.; Ren, X.; Chang, Y.; Wang, J.; Yu, L.; Dean, K. Generation of Microcellular Biodegradable Polycaprolactone Foams in Supercritical Carbon Dioxide. J. Appl. Polym. Sci. 2004, 94, 593-597. [CrossRef]

12. Kiran, E. Foaming Strategies for Bioabsorbable Polymers in Supercritical Fluid Mixtures. Part II. Foaming of Poly ( $\varepsilon$-caprolactone-co-lactide) in Carbon Dioxide and Carbon Dioxide + Acetone Fluid Mixtures and Formation of Tubular Foams via Solution Extrusion. J. Supercrit. Fluids 2010, 54, 308-319. [CrossRef]

13. Diaz-Gomez, L.; Concheiro, A.; Alvarez-Lorenzo, C.; García-González, C.A. Growth Factors Delivery from Hybrid PCL-Starch Scaffolds Processed Using Supercritical Fluid Technology. Carbohydr. Polym. 2016, 142, 282-292. [CrossRef] [PubMed]

14. de Matos, M.B.C.; Piedade, A.P.; Alvarez-Lorenzo, C.; Concheiro, A.; Braga, M.E.M.; de Sousa, H.C. Dexamethasone-loaded poly( $\varepsilon$-caprolactone)/Silica Nanoparticles Composites Prepared by Supercritical $\mathrm{CO}_{2}$ Foaming/Mixing and Deposition. Int. J. Pharm. 2013, 456, 269-281. [CrossRef] [PubMed]

15. Goimil, L.; Santos-Rosales, V.; Delgado, A.; Évora, C.; Reyes, R.; Lozano-Pérez, A.A.; Aznar-Cervantes, S.D.; Cenis, J.L.; Gómez-Amoza, J.L.; Concheiro, A.; et al. scCO 2 -Foamed Silk Fibroin Aerogel/Poly( -caprolactone) Scaffolds Containing Dexamethasone for Bone Regeneration. J. $\mathrm{CO}_{2}$ Util. 2019, 31, 51-64. [CrossRef]

16. Campardelli, R.; Franco, P.; Reverchon, E.; De Marco, I. Polycaprolactone/Nimesulide Patches Obtained by a One-Step Supercritical Foaming + Impregnation Process. J. Supercrit. Fluids 2019, 146, 47-54. [CrossRef]

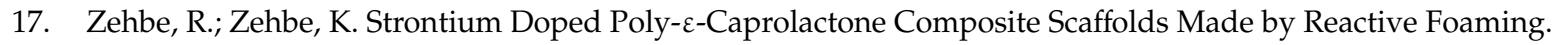
Mater. Sci. Eng. C 2016, 67, 259-266. [CrossRef] [PubMed]

18. Marković, D.; Milovanović, S.; Radovanović, Ž.; Zizovic, I.; Šaponjić, Z.; Radetić, M. Floating Photocatalyst Based on Poly( $\varepsilon$-caprolactone) Foam and $\mathrm{TiO}_{2}$ Nanoparticles for Removal of Textile Dyes. Fibers Polym. 2018, 19, 1219-1227. [CrossRef]

19. Tsivintzelis, I.; Pavlidou, E.; Panayiotou, C. Biodegradable Polymer Foams Prepared with Supercritical $\mathrm{CO}_{2}$-Ethanol Mixtures as Blowing Agents. J. Supercrit. Fluids 2007, 42, 265-272. [CrossRef]

20. Formica, J.V.; Regelson, W. Review of the Biology of Quercetin and Related Bioflavonoids. Food Chem. Toxicol. 1995, 33, 1061-1080. [CrossRef]

21. Boots, A.W.; Haenen, G.R.M.M.; Bast, A. Health Effects of Quercetin: From Antioxidant to Nutraceutical. Eur. J. Pharmacol. 2008, 585, 325-337. [CrossRef] [PubMed] 
22. Sahoo, N.G.; Kakran, M.; Shaal, L.A.; Li, L.; Müller, R.H.; Pal, M.; Tan, L.P. Preparation and Characterization of Quercetin Nanocrystals. J. Pharm. Sci. 2011, 100, 2379-2390. [CrossRef] [PubMed]

23. Santos, D.T.; Meireles, M.A.A. Micronization and Encapsulation of Functional Pigments Using Supercritical Carbon Dioxide. J. Food Process Eng. 2013, 36, 36-49. [CrossRef]

24. García-Casas, I.; Montes, A.; Pereyra, C.; Martínez, D.L.O.E.J. Generation of Quercetin/Cellulose Acetate Phthalate Systems for Delivery by Supercritical Antisolvent Process. Eur. J. Pharm. Sci. 2017, 100, 79-86. [CrossRef] [PubMed]

25. Dias, A.M.A.; Braga, M.E.M.; Seabra, I.J.; Ferreira, P.; Gil, M.H.; De Sousa, H.C. Development of Natural-Based Wound Dressings Impregnated with Bioactive Compounds and Using Supercritical Carbon Dioxide. Int. J. Pharm. 2011, 408, 9-19. [CrossRef] [PubMed]

26. García-Casas, I.; Crampon, C.; Montes, A.; Pereyra, C.; Martínez, D.L.O.E.J.; Badens, E. Supercritical CO 2 Impregnation of Silica Microparticles with Quercetin. J. Supercrit. Fluids 2019, 143, 157-161. [CrossRef]

27. Zhu, Y.F.; Shi, J.L.; Li, Y.S.; Chen, H.R.; Shen, W.H.; Dong, X.P. Storage and Release of Ibuprofen Drug Molecules in Hollow Mesoporous Silica Spheres with Modified Pore Surface. Microporous Mesoporous Mater. 2005, 85, 75-81. [CrossRef]

28. Dahmoune, F.; Spigno, G.; Moussi, K.; Remini, H.; Cherbal, A.; Madani, K. Pistacia lentiscus Leaves as a Source of Phenolic Compounds: Microwave-Assisted Extraction Optimized and Compared with Ultrasound-Assisted and Conventional Solvent Extraction. Ind. Crops Prod. 2014, 61, 31-40. [CrossRef]

29. Chafer, A.; Fornari, T.; Berna, A.; Stateva, R.P. Solubility of Quercetin in Supercritical $\mathrm{CO}_{2}+$ Ethanol as a Modifier: Measurements and Thermodynamic Modelling. J. Supercrit. Fluids 2004, 32, 89-96. [CrossRef]

30. Baldwin, D.F.; Park, C.B.; Suh, N.P. A microcellular Processing Study of Poly(ethylene terephthalate) in the Amorphous and Semicrystalline States. Part II: Cell Growth and Process Design. Polym. Eng. Sci. 1996, 36, 1446-1453. [CrossRef]

31. Reverchon, E.; Cardea, S. Production of Controlled Polymeric Foams by Supercritical $\mathrm{CO}_{2}$. J. Supercrit. Fluids 2007, 40, 144-152. [CrossRef]

32. Messersmith, P.B.; Giannelis, E.P. Synthesis and Barrier Properties of Poly( $\varepsilon$-caprolactone)-Layered Silicate Nanocomposites. J. Polym. Sci. Part A Polym. Chem. 1995, 33, 1047-1057. [CrossRef]

33. Fraile, M.; Buratto, R.; Gómez, B.; Martín, Á.; Cocero, M.J. Enhanced Delivery of Quercetin by Encapsulation in Poloxamers by Supercritical Antisolvent Process. Ind. Eng. Chem. Res. 2014, 53, 4318-4327. [CrossRef]

34. White, L.J.; Hutter, V.; Tai, H.; Howdle, S.M.; Shakesheff, K.M. The Effect of Processing Variables on Morphological and Mechanical Properties of Supercritical $\mathrm{CO}_{2}$ Foamed Scaffolds for Tissue Engineering. Acta Biomater. 2012, 8, 61-71. [CrossRef]

35. Tsivintzelis, I.; Angelopoulou, A.G.; Panayiotou, C. Foaming of Polymers with Supercritical $\mathrm{CO}_{2}: \mathrm{An}$ Experimental and Theoretical Study. Polymer 2007, 48, 5928-5939. [CrossRef] 